\title{
Differential Banding Pattern Based Identification of Urinary Tract Infection Causing Bacteria
}

\author{
${ }^{1}$ Poulomi Nandy, ${ }^{1}$ Md Aftabuddin, ${ }^{2}$ Ashoke Ranjan Thakur and ${ }^{1}$ Shaon RayChaudhuri \\ ${ }^{1}$ Department of Biotechnology, School of Biotechnology and Biological Sciences, \\ West Bengal University of Technology, BF-142, Sector-1, Salt Lake, Kolkata-700064, West Bengal, India \\ ${ }^{2}$ Vice Chancellor's Office, Techno India University, EM4/1, Sector V, Salt Lake, Kolkata-700091, West Bengal, India \\ Received 2012-12-07, Revised 2013-04-22; Accepted 2013-05-07
}

\begin{abstract}
Urinary Tract Infection (UTI) affects all age groups, but women are more susceptible than men. These infections are typically caused by E coli, Proteus mirabilis, Staphylococcus aureus, Klebsiella pneumoniae, Pseudomonas aeruginosa, Enterococcus fecalis and so on. Since uncultivable microbes are numerically abundant in urine samples, culture independent detection seems to be the method of choice for diagnosing UTI. This study was an attempt to design a database of banding pattern of microbial variety inhabiting normal and infected subjects. The 16S rDNA Polymerase Chain Reaction (PCR) product was digested with 14 different restriction enzymes and run on a $2 \%$ agarose gel. From the restriction digestion images, their banding pattern and dendogram analysis, it was possible to differentiate and distinguish between E.coli, Pseudomonas, Klebsiella, Staphylococcus and Enterococci genus. Most of the enzymes like XbaI, ApaI, KpnI, PstI gave similar banding patterns for Klebsiella, E.coli and Pseudomonas, which could be differentiated from the Staphylococcus members. BgII and SmaI gave similar patterns for Klebsiella and E.coli, which was in turn different from that of Pseudomonas and Staphylococcus. Enzyme BamHI not only differentiated among Staphylococcus and the other three groups but was also able to show a distinct variation in banding pattern among Staphylococcus members. The database generated was used to identify pathogens from unknown patient samples without cultivating them. HindIII and HinfI can be used as two separate potential enzymes to differentiate and distinguish between the various microbes.
\end{abstract}

Keywords: Culture Independent, Dendogram, RFLP, UTI

\section{INTRODUCTION}

The urinary tract is one of the most common site of bacterial infection in humans. It is exacerbated amongst female population because of poor hygienic conditions prevailing in third world countries where gender bias in social groups already puts the women as a disadvantaged group (August and Rosa, 2012). Uncultivable microbes are numerically dominant in urine samples and therefore have to be detected by culture independent methods. One of the major drawbacks of the routine diagnostic methods for Corresponding Author: Shaon RayChaudhuri, Department of Biotechnology, School of Biotechnology and Biological Sciences, West Bengal University of Technology, BF-142, Sector-1, Salt Lake, Kolkata-700064, West Bengal, India pathogen identification in UTI and Septicaemia is the long period for detection $(48-72 \mathrm{~h})$ required in culture based methods. The use of culture independent molecular diagnostics may provide a solution for prognostic intervention of this disease which has a high morbidity and mortality rate. Molecular biology techniques for correct detection and identification of bacteria is now widely used in clinical microbiology namely $16 \mathrm{~S}$ rRNA based identification, Restriction Fragment Length Polymorphism (RFLP) (Wang et al., 2010; Moreno et al., 2008; Shokohi et al., 2010; Zhang et al., 1997; Zingler et al., 1992; Silveira et al., 4 
2001; Kassama et al., 2002; Jordens and Hall, 1988; Messaoudi et al., 2009). As epidemiology, virulence, antibacterial susceptibility often vary among strains, a rapid and accurate identification of the species causing the disease is crucial for treatment and epidemiological studies. Taxonomists today consider analysis of an organism's DNA more reliable than classification based solely on phenotypes. The $16 \mathrm{~S}$ rDNA gene (codes for small subunit of ribosome) is a section of prokaryotic DNA found in all bacteria and archaea. Secondly, the gene is distinct and conserved over time. Thirdly, the gene is short around $1.5 \mathrm{~kb}$ making it easier and cheaper to sequence. Moreover, assessing the entire population via PCR amplification of a specific genetic sequence, avoids sample size biases. Bacterial 16S rDNA genebased terminal RFLP is one of the molecular methods to visualize complex microbial communities. This molecular approach, which by detecting a fluorescently labeled fragment of the PCR-amplified 16S rDNA gene, has enabled rapid analysis of the total composition of bacterial samples that include a variety of microorganisms (Dekio et al., 2007; Mehndiratta et al., 2009; Sakamoto et al., 2003; Rogers et al., 2006). Thus this method not only identifies the disease causing bacteria but also permits an accurate determination of its relative abundance in the community which is vital for correct clinical procedures to be adopted for treatment.

\section{MATERIALS AND METHODS}

\subsection{Strains used for the Study, Genomic DNA Isolation and 16S rDNA PCR Amplification}

A total number of 16 different strains isolated from the various female urine samples screened by culture dependent method were used to generate the differential banding pattern database. The method of isolation and detailed characterization of the strains have already been reported earlier (Nandy et al., 2007; 2009; RayChaudhuri et al., 2008). The isolates used for the study were, SRC A-Staphylococcus hemolyticus (99.89\%), SRC_C-Ǩlebsiella pneumonia (99.6\%), SRC_D-Staphylococcus aureus (100\%), SRC_EPseudomonas aeruginosa (100\%), SRC_F-Escherichia coli (100\%), SRC_H-Klebsiella pneumonia (99.6\%), SRC_J-Staphylococcus hemolyticus (99.58\%), SRC_KEscherichia coli (100\%), SRC_L-Staphylococcus aureus (100\%), SRC_M-Klebsiella pneumonia (99.62\%), SRC_N-Staphylococcus sciuri (100\%), SRC_OKlebsiella pneumonia (99.57\%), SRC_P-Staphylococcus aureus (100\%), SRC_S-Staphylococcus epidermis (100\%), SRC_R-Enterococci fecalis (100\%). The percentage similarity of the various isolates with its closest cultivable neighbour through partial 16S rDNA sequence analysis, obtained by GenBank BLAST analysis, is mentioned within parenthesis. Genomic DNA was isolated by modified alkali lysis method of RayChaudhuri and Thakur (2006). Bacterial primers mentioned below were used for amplification of $16 \mathrm{~S}$ rDNA fragment. Forward primer-5' AGA GTT TGA TCA TGG CTC 3', Reverse primer - 5' CTA GCG ATT CCG ACT TCA 3'. The reaction mixture for PCR amplification was prepared using PCR Ready Mix (Sigma)-12.5 $\mu \mathrm{L}$, Forward Primer-0.25 $\mu \mathrm{L}$ (from $50 \mathrm{pmole} / \mu \mathrm{L}$ stock), Reverse Primer-0.25 $\mu \mathrm{L}$ (from $50 \mathrm{pmole} / \mu \mathrm{L}$ stock), Triple distilled water-Variable, DNA (template)-20-30 ng. The mix was subjected to 40 cycles of PCR amplification according to the program: Initial denaturation $92^{\circ} \mathrm{C}-2$ min then 40 cycles of $92^{\circ} \mathrm{C}-1 \mathrm{~min}$; $50^{\circ} \mathrm{C}-1 \mathrm{~min} ; 72^{\circ} \mathrm{C}-2 \mathrm{~min}$ and final hold at $4^{\circ} \mathrm{C}$.

\subsection{Restriction Fragment Length Polymorphism of 16S rDNA PCR Products}

The PCR product was digested by 14 different restriction enzymes, as depicted in Table $\mathbf{1}$, to observe the banding pattern. $1 \mu \mathrm{L}$ of $10 \mathrm{X}$ assay buffer, $1 \mu \mathrm{L}$ of enzyme, $13 \mu \mathrm{L}$ of nuclease free sterile water, $0.4 \mu \mathrm{g}$ PCR product were mixed. The suspension was kept for incubation at their respective temperatures in a water bath for $16 \mathrm{~h}$. The enzyme was inactivated by keeping the mixture at its respective temperature mentioned in Table 1. The entire product was analyzed in a 2\% gel with 50bp (Fermentas Sm0613), 100bp (Fermentas SM0623) and 500bp (Fermentas SM0643) DNA ladders from Fermentas.

\subsection{Regarding the Database}

A database was created and hosted at http://www.wbut.ac.in/rflbmd. The address has been so selected that only the developer can access it as the url is not obvious and is not circulated outside the circle of investigators. The images (gel and dendogram) as well as data regarding the experimental condition are stores in MySQL database. The front end has been created using PHP and HTML while the back end is running on Apache Webserver. The OS is linux. All the software used is Opensource. The search Engine could be developed in due course of time. Now the data generated by other investigators have to be manually compared with that in the database but with the development of the search engine using image processing techniques, the data from the investigator could be uploaded and compared with the database automatically. 
Table 1. Details of the restriction digestion enzymes as well as reaction condition used for the study

\begin{tabular}{lllll}
\hline Enzyme & Fermentas catalogue No. & Concentration & Incubation temperature & Inactivation temperature and time \\
\hline ApaI & ER1411 & $10 \mathrm{u} / \mu \mathrm{L}$ & $37^{\circ} \mathrm{C}$ & $65^{\circ} \mathrm{C} ; 20 \mathrm{~min}$ \\
BamHI & ER0051 & $10 \mathrm{u} / \mu \mathrm{L}$ & $37^{\circ} \mathrm{C}$ & $65^{\circ} \mathrm{C} ; 20 \mathrm{~min}$ \\
BgII & ER0071 & $10 \mathrm{u} / \mu \mathrm{L}$ & $37^{\circ} \mathrm{C}$ & $65^{\circ} \mathrm{C} ; 20 \mathrm{~min}$ \\
EcoRI & ER0271 & $10 \mathrm{u} / \mu \mathrm{L}$ & $37^{\circ} \mathrm{C}$ & $65^{\circ} \mathrm{C} ; 20 \mathrm{~min}$ \\
HindIII & ER0501 & $10 \mathrm{u} / \mu \mathrm{L}$ & $37^{\circ} \mathrm{C}$ & $80^{\circ} \mathrm{C} ; 20 \mathrm{~min}$ \\
HinfI & ER0801 & $10 \mathrm{u} / \mu \mathrm{L}$ & $37^{\circ} \mathrm{C}$ & $65^{\circ} \mathrm{C} ; 20 \mathrm{~min}$ \\
KpnI & ER0521 & $10 \mathrm{u} / \mu \mathrm{L}$ & $37^{\circ} \mathrm{C}$ & $80^{\circ} \mathrm{C} ; 20 \mathrm{~min}$ \\
NotI & ER0591 & $10 \mathrm{u} / \mu \mathrm{L}$ & $37^{\circ} \mathrm{C}$ & $80^{\circ} \mathrm{C} ; 20 \mathrm{~min}$ \\
PstI & ER0611 & $10 \mathrm{u} / \mu \mathrm{L}$ & $37^{\circ} \mathrm{C}$ & $80^{\circ} \mathrm{C} ; 20 \mathrm{~min}$ \\
PvuII & ER0631 & $10 \mathrm{u} / \mu \mathrm{L}$ & $37^{\circ} \mathrm{C}$ & $80^{\circ} \mathrm{C} ; 20 \mathrm{~min}$ \\
SacI & ER1131 & $10 \mathrm{u} / \mu \mathrm{L}$ & $37^{\circ} \mathrm{C}$ & $65^{\circ} \mathrm{C} ; 20 \mathrm{~min}$ \\
SgsI & ER1891 & $10 \mathrm{u} / \mu \mathrm{L}$ & $37^{\circ} \mathrm{C}$ & $65^{\circ} \mathrm{C} ; 20 \mathrm{~min}$ \\
SmaI & ER0661 & $10 \mathrm{u} / \mu \mathrm{L}$ & $30^{\circ} \mathrm{C}$ & $65^{\circ} \mathrm{C} ; 20 \mathrm{~min}$ \\
XbaI & ER0681 & $10 \mathrm{u} / \mu \mathrm{L}$ & $37^{\circ} \mathrm{C}$ & $65^{\circ} \mathrm{C} ; 20 \mathrm{~min}$ \\
\hline
\end{tabular}

\subsection{Using the Database to Identify Unknown Pathogens in UTI Patients by Culture Independent Method}

In order to confer whether the microbes present in urine samples could be determined in absence of cultivation, $1.5 \mathrm{~mL}$ of four randomly picked up patient samples (obtained from Peerless Hospitals) were centrifuged for $10 \mathrm{~min}$ at $10,000 \mathrm{~g}$. DNA was extracted from the pellet obtained by using Fit Amp Urine DNA isolation kit as per the manufacturer's protocol (Epigentek, P-1017-050). Then it was subjected to PCR amplification using bacterial primers as described above. The PCR product obtained was used for restriction digestion using Hind III enzyme. To compare the different bands present in the community profile obtained from urine samples, a mixed PCR template (containing SRC_A, SRC_C, SRC_D, SRC_E, SRC_F, SRC_N and SRC_S in equal proportion, thus representing each variety) was also digested by Hind III and run in parallel to the unknown samples along with a 50 and $100 \mathrm{bp}$ marker.

\section{RESULTS}

From the restriction digestion images (Fig. 1a-n) and banding pattern analysis as depicted in Table 2, using 14 different enzymes we found that HindIII and HinfI can be used as two separate potential enzymes to differentiate and distinguish between E.coli,
Pseudomonas, Klebsiella and Staphylococcus genus. Table 2 clearly points out the variation in bands (measured in base pairs) among the isolates, within the 1350bp 16S rDNA PCR amplified region on digestion with different enzymes. The dendogram analysis of the gel images was also done using UVP Image Analysis software, to determine the percentage variation in the banding pattern among the isolates. Figure 2 represents the restriction digestion banding pattern of isolate SRC_R (Enterococci fecalis) using the 14 different enzymes, which depicts the probable use of enzyme HinfI to differentiate it among other isolates. As evident from Fig. 3, the bands present in the mixed sample (obtained by digestion of PCR amplicons of each variety of urinary micro flora previously isolated by culture dependent method) lane (lane 11 and 12) correspond to nearly $100,250,550,600,650,1000$, 1100,1300 and $1350 \mathrm{bp}$. It also matches to the band lengths depicted in Table 2, for each of the individual microbes. By comparing the band lengths obtained in case of the 4 patient samples with the data given in Table 2, we can easily infer to the causative agent of infection; for e.g., for patient sample 2 (lane 3 and 4) showing bands at 550, 600 and $650 \mathrm{bp}$ nearly corresponds to $E$ coli. A similar picture is reflected by patient sample 6 (lane 7 and 8) and patient sample 10 (lane 9 and 10) showing bands at 600, 650 and 1350bp, thus corresponding to $E$ coli infection. While for patient sample 3 (lane 5 and 6 ) the only bands present are near $1300 \mathrm{bp}$ and $1350 \mathrm{bp}$, which correspond to Klebsilella infection by certain specific strains. 
Poulomi Nandy et al. / American Journal of Biochemistry and Biotechnology, 9 (2): 124-132, 2013

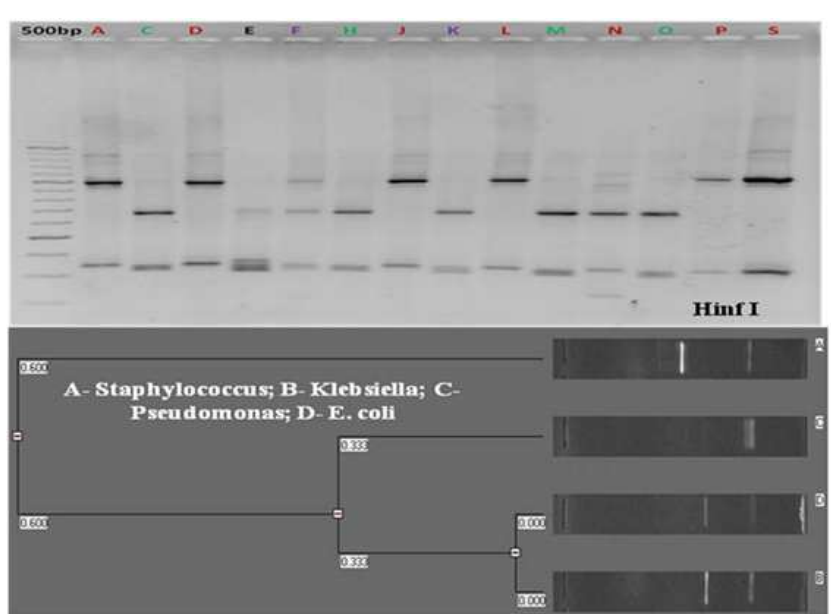

(a)

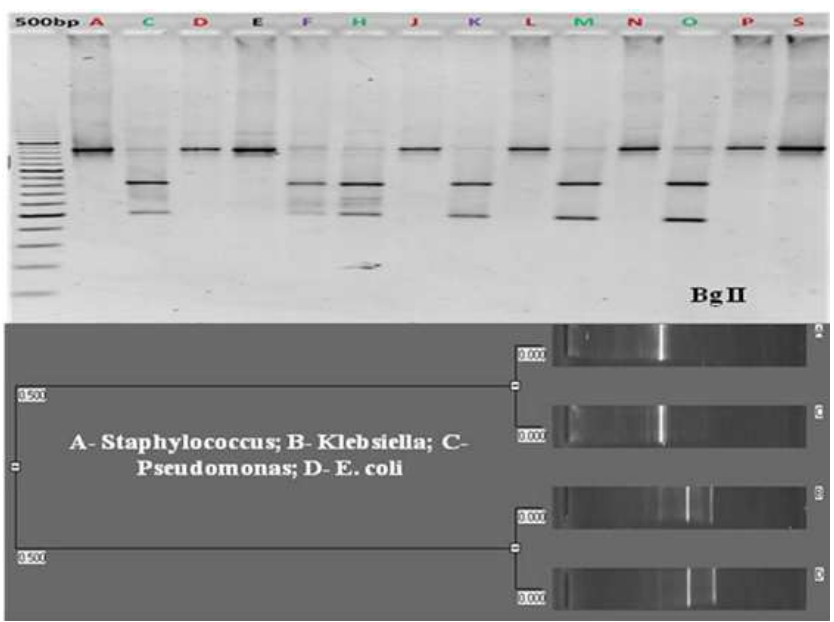

(c)

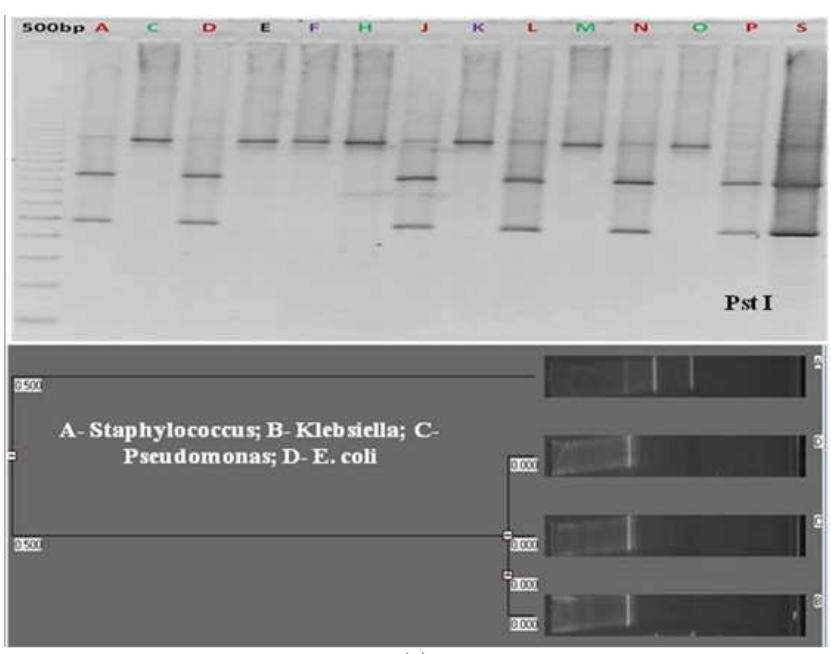

(e)

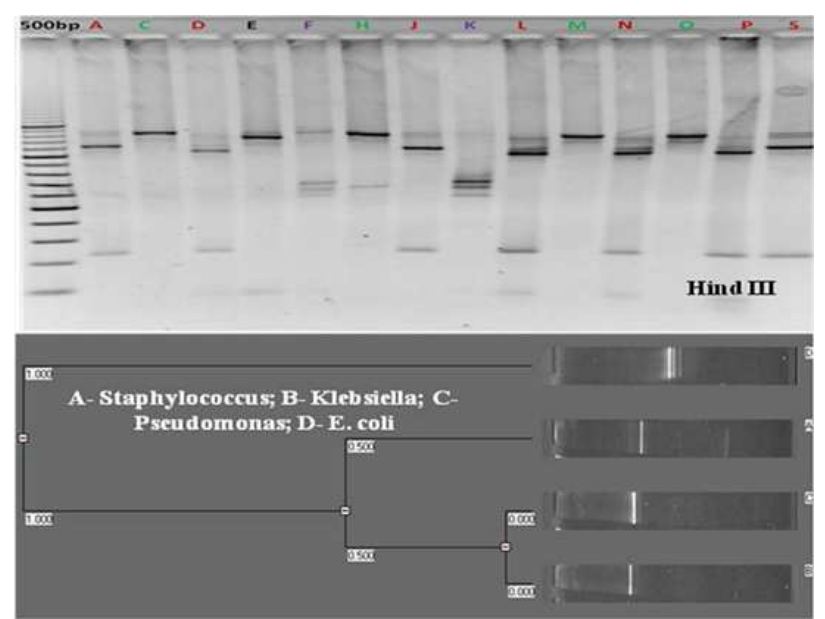

(b)

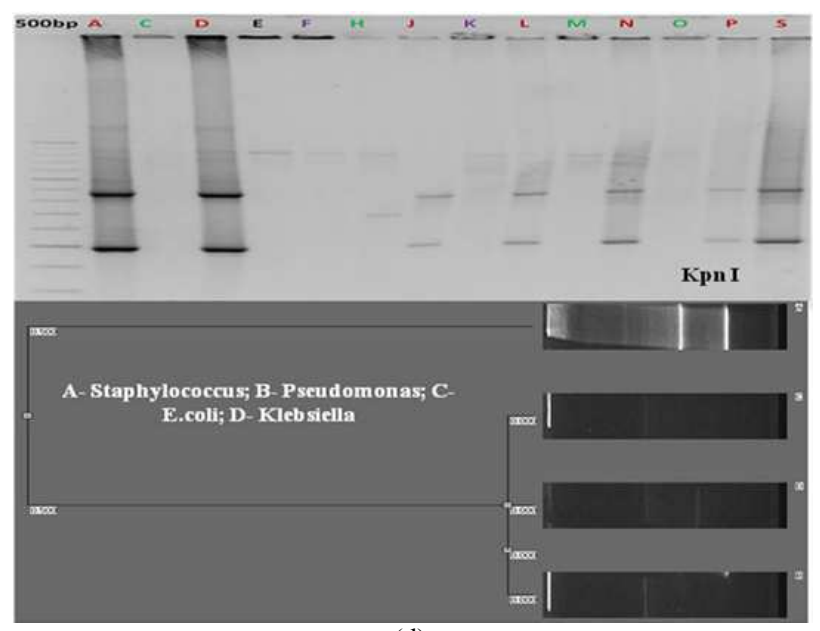

(d)

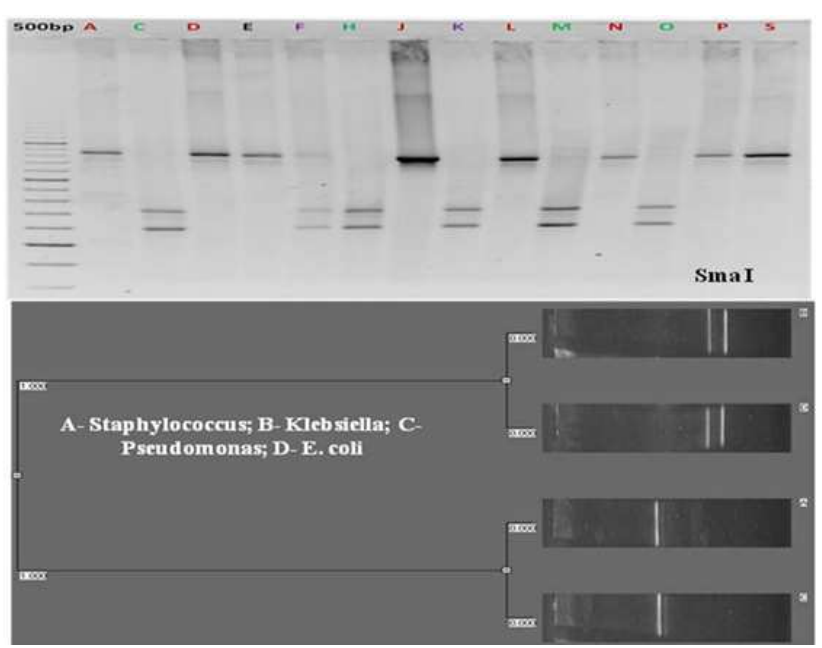

(f) 
Poulomi Nandy et al. / American Journal of Biochemistry and Biotechnology, 9 (2): 124-132, 2013

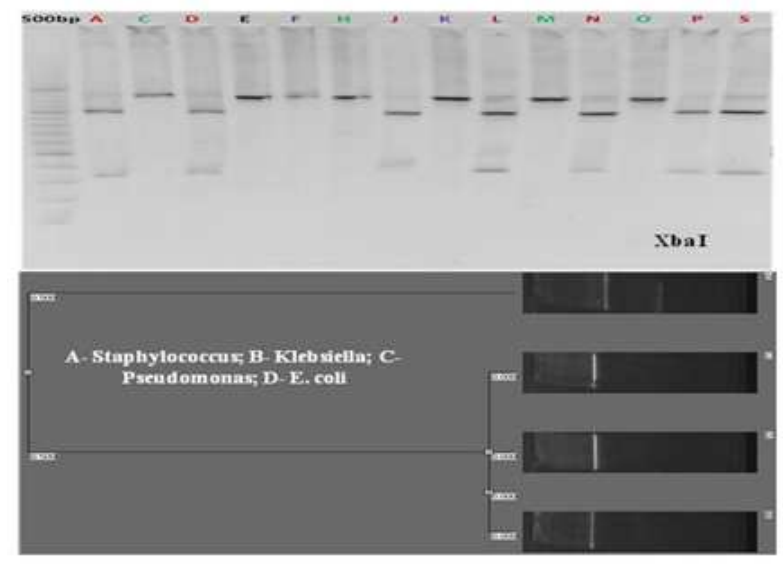

(g)

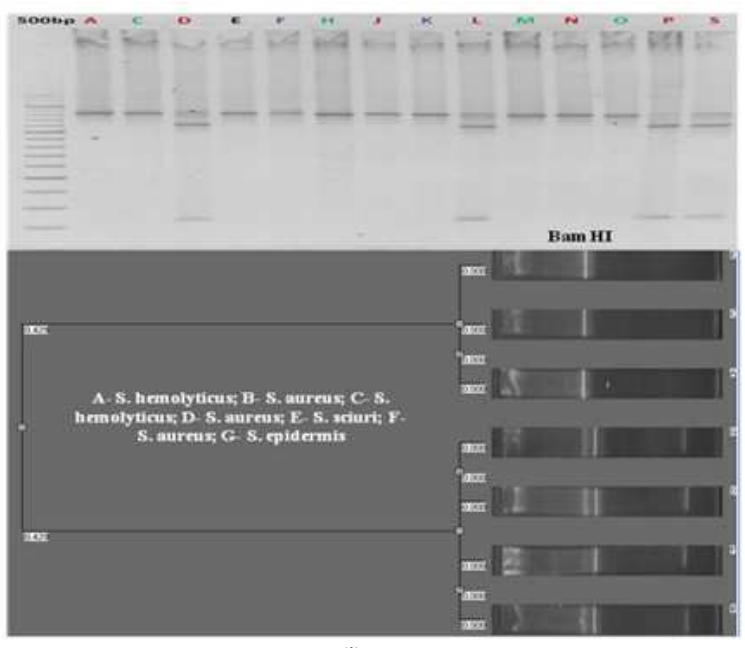

(i)

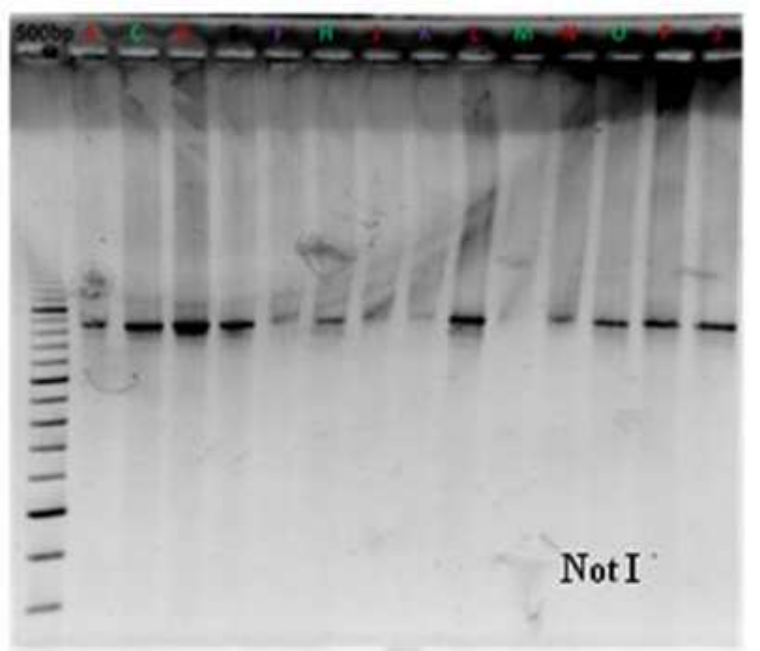

(k)

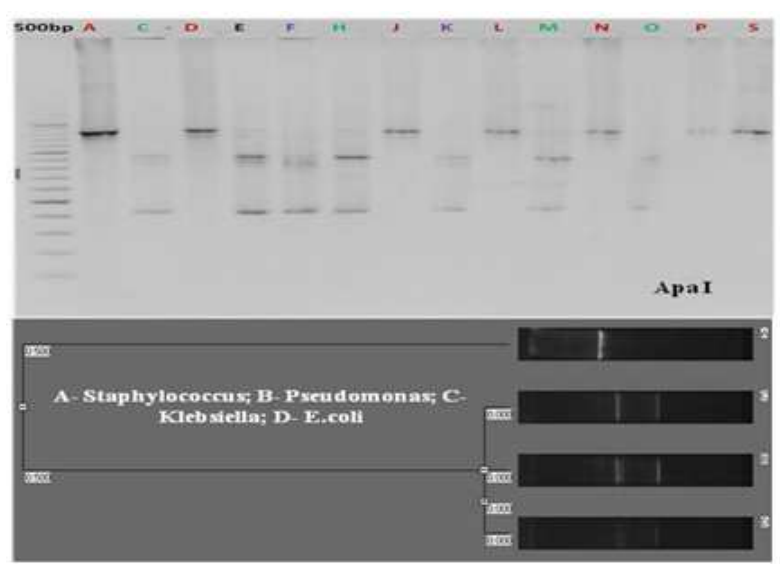

(h)

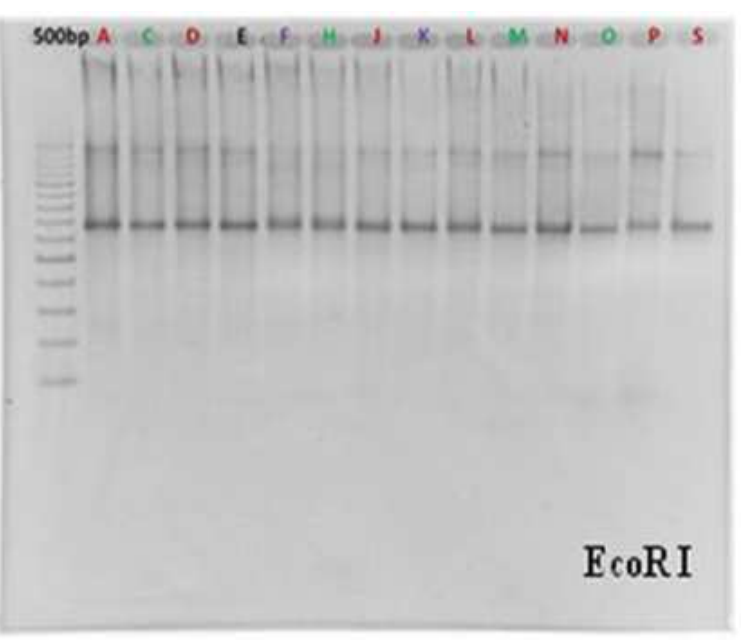

(j)

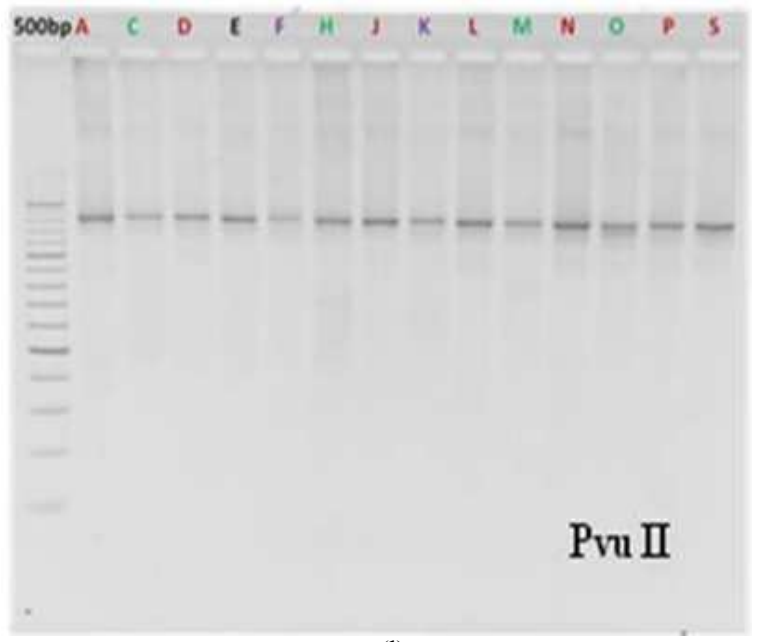

(1) 


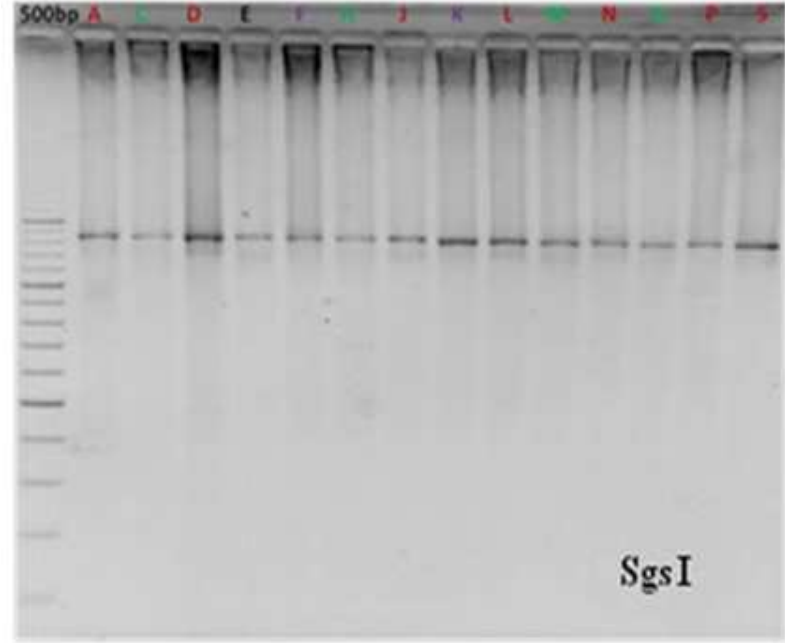

(m)

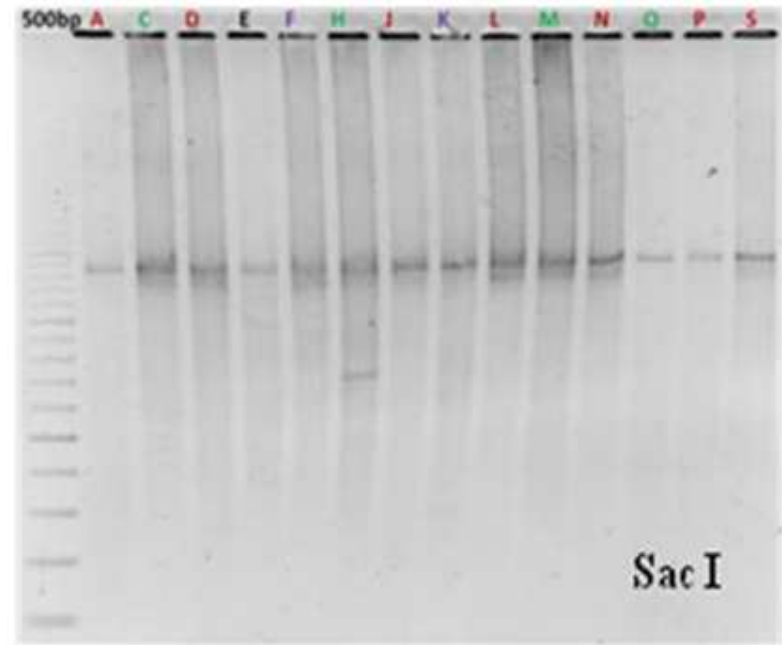

(n)

Fig. 1a-n. Banding pattern analysis of UTI causing isolates. The restriction digestion products were run on a $2 \%$ agarose gel at $100 \mathrm{Volts} / \mathrm{cm}$ for $4 \mathrm{~h}$ and the image was captured in an UVP BioDoc-It Imaging system post Ethidium bromide staining. The dendograms were constructed using UVP Image Analysis software. The lanes 2-14 stand for restriction digested product of isolates A-S.hemolyticus; C-K.pneumoniae; D-S.aureus; E-P.aeruginosa; F-E.coli; H-K.pneumoniae; J-S.hemolyticus; K-E.coli; L-S.aureus; M-K.pneumoniae; N-S.sciuri; O-K.pneumoniae; PS.aureus; S-S.epidermis

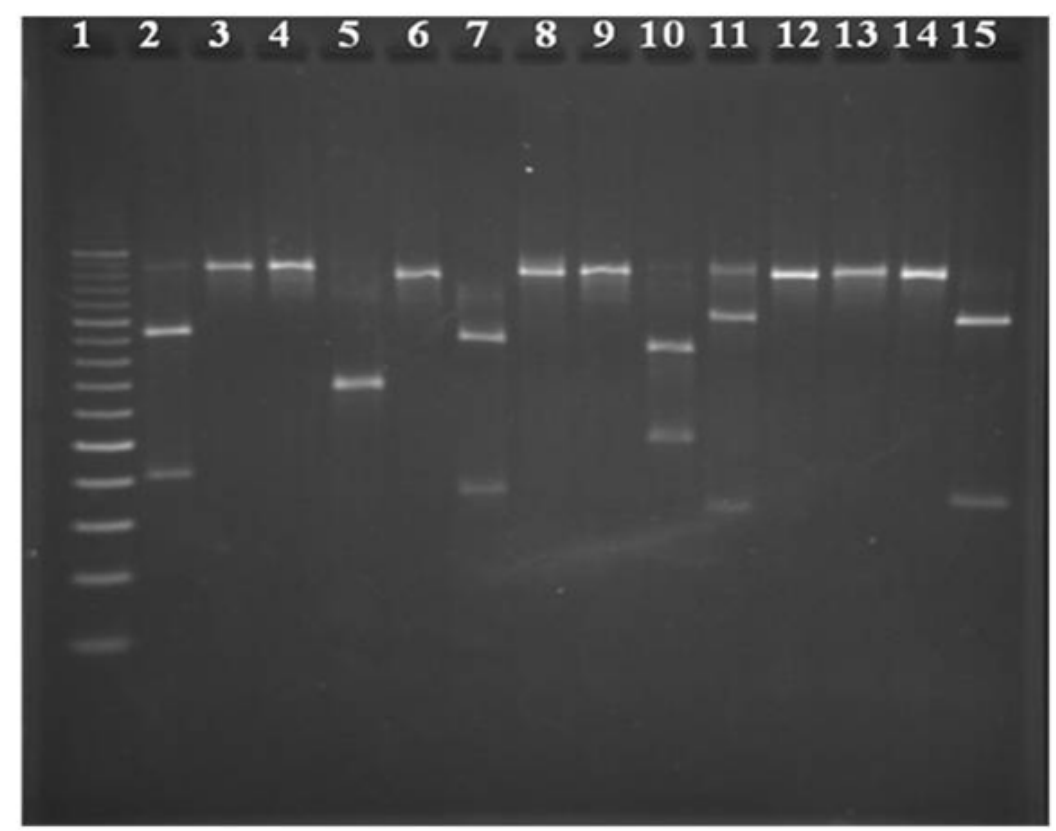

Fig 2. 2\% Agarose gel picture of Restriction digestion analysis of Enterococci fecalis using the 14 different enzymes. Lane 1 is 100bp marker, Lane 2 to 15 represent the post digestion banding pattern of 16S rDNA PCR product using enzymes ApaI, BamHI, BgII, EcoRI, HindIII, HinfI, KpnI, NotI, PstI, PvuII, SacI, SgsI, SmaI and XbaI 


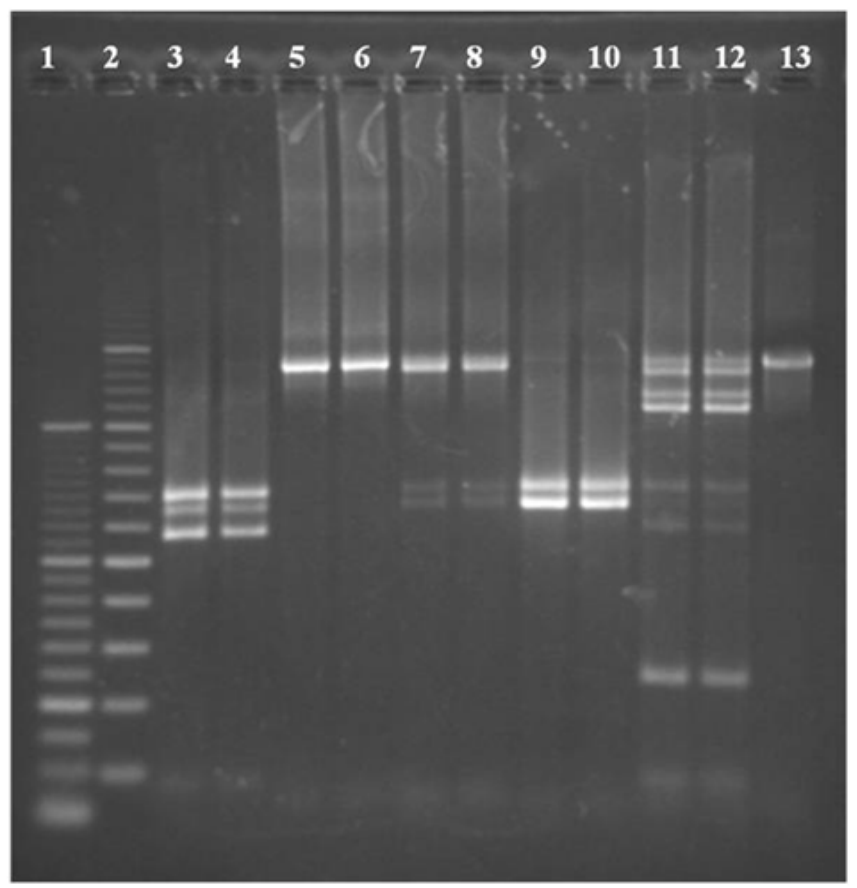

Fig. 3. $2 \%$ Hind III Restriction digestion gel analysis of patient urine samples by culture independent method. Lane 1 and 2 are $50 \mathrm{bp}$ and 100bp markers, lane 3 and 4 are replicates for patient sample 2; lane 5 and 6 are replicates for patient sample 3; lane 7 and 8 are replicates for patient sample 6; lane 9 and 10 are replicates for patient sample 10; lane 11 and 12 are replicates for mixed microbial sample; lane 13 is a representative 16S rDNA bacterial PCR amplicon of the urine samples at 1350bp

Table 2. List of the different band sizes in base pairs for the isolates post restriction digestion on a $2 \%$ agarose gel following electrophoresis run at 100 Volts $/ \mathrm{cm}$ for $4 \mathrm{~h}$

\begin{tabular}{llllllll}
\hline Enzyme & Klebsiella & E.coli & Pseudomonas & S.aureus & S.hemolyticus & S.epidermis & S.sciuri \\
\hline HinfI & $320,340,650$, & $320,340,650$, & $320,340,350$, & $350,950,1000$, & $350,950,1000$, & $350,950,1000$, & $200,350,650$, \\
& 1350 & 1000,1350 & 650,1350 & 1300,1350 & 1300,1350 & 1300,1350 & $950,1000,1100$, \\
& & & & & & 1300,1350 \\
HindIII & $600 *, 1300$, & $550,600,650$, & $100,1300,1350$ & $100,250,1100$, & 250,1100, & 250,1100, & $100,250,1100$, \\
& 1350 & 1350 & & 1300,1350 & 1300,1350 & 1300,1350 & 1300,1350 \\
BgII & $500,650,800$, & $500,650,800$, & 1350 & 1350 & 1350 & 1350 & 1350 \\
& 1300,1350 & 1300,1350 & & & & \\
KpnI & 1300,1350 & 1300,1350 & 1300,1350 & 500,850, & 500,850, & 500,850, & 500,850, \\
& & & 1350,1350 & 1300,1350 & 1300,1350 & 1300,1350 \\
PstI & 1350 & 1350 & 1350 & $500,800,1350$ & $500,800,1350$ & $500,800,1350$ & $500,800,1350$ \\
SmaI & 600,700, & 600,700, & 1300,1350 & 1300,1350 & 1300,1350 & 1300,1350 & 1300,1350 \\
& 1300,1350 & 1300,1350 & & & & & \\
XbaI & 1350 & 1350 & 1350 & 350,1000, & 350,1000, & 350,1000, & 350,1000, \\
& & & 1300,1350 & 1300,1350 & 1300,1350 & 1300,1350 \\
ApaI & $400,900,1350$ & $400,900,1350$ & $400,900,1350$ & 1350 & 1350 & 1350 & 1350 \\
BamHI & 1300,1350 & 1300,1350 & 1300,1350 & 250,1100, & 1300,1350 & 250,1100, & 1300,1350 \\
& & & & 1300,1350 & & 1300,1350 & \\
EcoRI & 650,1300, & 650,1300, & 650,1300, & 650,1300, & 650,1300, & 650,1300, & 650,1300, \\
& 1350 & 1350 & 1350 & 1350 & 1350 & 1350 & 1350 \\
NotI & 1350 & 1350 & 1350 & 1350 & 1350 & 1350 & 1350 \\
PvuII & 1350 & 1350 & 1350 & 1350 & 1350 & 1350 & 1350 \\
SgsI & 1350 & 1350 & 1350 & 1350 & 1350 & 1350 & 1350 \\
SacI & 1350 & 1350 & 1350 & 1350 & 1350 & 1350 & 1350 \\
\hline
\end{tabular}

*In case of some Klebsiella strains, like for SRC_M, the 600bp band was not present. 


\section{DISCUSSION}

Most of the enzymes like XbaI, ApaI, KpnI, PstI gave similar banding patterns for Klebsiella, E.coli and Pseudomonas, which could be differentiated from the Staphylococcus members. BgII and SmaI gave similar patterns for Klebsiella and E coli, which was in turn different from that of Pseudomonas and Staphylococcus. All these enzymes could only help us in identifying amongst different genus of the UTI causing isolates. But one interesting finding was that enzyme BamHI not only differentiated among Staphylococcus and the other three groups but was also able to show a distinct variation in banding pattern among Staphylococcus members; i.e., S. hemolyticus and $S$. sciuri gave bands at 1300 and 1350 bp only, while $S$. aureus and S. epidermis gave additional bands at 250 and $1100 \mathrm{bp}$. EcoRI had the same restriction sites for all the isolates. But enzymes like NotI, PvuII, SgsI and SacI did not find any restriction site among all the organisms, so the only band was at $1350 \mathrm{bp}$ corresponding to the $16 \mathrm{~S}$ rDNA PCR product. For Enterococci sp. most of the enzymes like BamHI, BgII, HindIII, KpnI, NotI, SacI, SgsI, SmaI fail to find any restriction site. It shows a similar banding pattern for enzymes ApaI, HinfI, PvuII and XbaI with bands at 400, 900, 1350bp; while EcoRI gave bands at 650 , $1350 \mathrm{bp}$ and PstI at 500, 800 and $1350 \mathrm{bp}$ nearly. Thus EcoRI gives a similar pattern as for the other isolates also, while for PstI, it shows a similarity with the Staphylococcal isolates. For ApaI, it is in accordance with the non Staphylococcal group, for XbaI and PvuII, it gives an altogether different pattern from all the isolates; while HinfI can be used as the enzyme for differentiating Enterococci from other isolates since it gives bands at 400 and $900 \mathrm{bp}$ while are not present in case of the other members of the urinary tract micro flora. The above data that was accumulated was sent for the development of a database, so that others working in similar field could utilize this as a reference for interpretation of their experimental results. It is a user friendly interactive interface. The agarose gel electrophoresis image along with their respective dendogram and the experimental conditions were provided in the database for each of the restriction enzymes. The database can be accessed at the following link: http:// wbut.ac.in/rflbmd/.

\section{CONCLUSION}

The above study reports a user friendly database for reference to promptly identify the causative organism in case of clinical conditions like UTI as well as septicemis. This would minimise the time required for detection as compared to the culture based method and thus ensuring prompt medical intervension during critical situations.

\section{ACKNOWLEDGEMENT}

The researchers acknowledge the support of the West Bengal University of Technology for the computational facility and the laboratories; University Grant Commission-Inter University Consortium as well as Department of Atomic Energy, Government of India under the BRNS scheme for the student fellowship and Department of Atomic Energy, Government of India under the BRNS scheme for financial assistance. The authors would like to thank Mr Sourav Ghosh for formatting of the paper. The authors are greatful to World bank sponsored TEQIP program for providing the publication fee.

\section{REFERENCES}

August, S.L. and M.J.D. Rosa, 2012. Evaluation of the prevalence of urinary tract infection in rural panamanian women. Plos One, 7: e47752-e47752. DOI: 10.1371/journal.pone.0047752

Dekio, I., M. Sakamoto, H. Hayashi, M. Amagai and M. Seumatsu et al., 2007. Characterization of skin microbiota in patients with atopic dermatitis and in normal subjects using 16S rRNA gene-based comprehensive analysis. J. Med. Microbiol., 56: 1675-1683. DOI: 10.1099/jmm.0.47268-0

Jordens, J.Z. and L.M. Hall, 1988. Characterisation of methicillin-resistant Staphylococcus aureus isolates by restriction endonuclease digestion of chromosomal DNA. J. Med. Microbiol., 27: 117123. PMID: 2845089

Kassama, Y., P.J. Rooney and R. Goodacre, 2002. Fluorescent amplified fragment length polymorphism probabilistic database for identification of bacterial isolates from urinary tract infections. J. Clin. Microbiol., 40: 2795-2800. DOI: 10.1128/JCM.40.8.2795-2800.2002 
Mehndiratta, P.L., P. Bhalla, A. Ahmed and Y.D. Sharma, 2009. Molecular typing of methicillinresistant Staphylococcus aureus strains by PCRRFLP of SPA gene: A reference laboratory perspective. Ind. J. Med. Microbiol., 27: 116-122. DOI: $10.4103 / 0255-0857.45363$

Messaoudi, A., M. Gtari, A. Boudabous and F. Wagenlehner, 2009. Identification and susceptibility of Klebsiella and Enterobacter spp. Isolated from meat products. Afr. J. Microbial. Res., 3: 362-369.

Moreno, E., A. Andreu, C. Pigrau, M.A. Kuskowski and J.R. Johnson et al., 2008. Relationship between Escherichia coli strains causing acute cystitis in women and the Fecal E. coli population of the host. J. Clin. Microbiol., 46: 2592-2534. DOI: 10.1128/JCM.00813-08

Nandy, P., A.R. Thakur and S.R. Chaudhuri, 2007. Characterization of bacterial strains isolated through microbial profiling of urine samples. Online J. Biol. Sci., 7: 44-51. DOI: 10.3844/ojbsci.2007.44.51

Nandy, P., S. Roy, A.R. Thakur and S.R. Chaudhuri, 2009. Comparative study on characterization of three Staphylococcal isolates from varied origin. J. Culture Collect., 6: 52-60.

RayChaudhuri, S. and A.R. Thakur, 2006. Microbial DNA extraction from samples of varied origin. Curr. Sci., 12: 1697-1700.

RayChaudhuri, S., A.R. Thakur, P. Nandy and S. Samanta, 2008. Urinary tract infection-A survey of local population. Am. J. Infect. Dis., 4: 117-123. DOI: 10.3844/ajidsp.2008.117.123

Rogers, G.B., M.P. Carroll, D.J. Serisier, P.M. Hockey and G. Jones et al., 2006. Use of 16S rRNA gene profiling by terminal restriction fragment length polymorphism analysis to compare bacterial communities in sputum and mouthwash samples from patients with cystic fibrosis. J. Clin. Microbiol., 44: 2601-2604. DOI: 10.1128/JCM.02282-05
Sakamoto, M., Y. Takeuchi, M. Umeda, I. Ishikawa and Y. Benno, 2003. Application of terminal RFLP analysis to characterize oral bacterial flora in saliva of healthy subjects and patients with periodontitis. J. Med. Microbiol., 52: 79-89. PMID: 12488570

Shokohi, T., M.B.H. Soteh, Z.S. Pouri, M.T. Hedayati and S. Mayahi, 2010. Identification of Candida species using PCR-RFLP in cancer patients in Iran. Ind. J. Med. Microbiol., 28: 147-151. DOI: 10.4103/0255-0857.62493

Silveira, W.D., F. Benetti, M. Lancellotti, A. Ferreira and V.N. Solferini et al., 2001. Biological and genetic characteristics of uropathogenic Escherichia coli strains. Rev. Inst. Med. Trop. S. Paulo., 43: 303310. PMID: 11781598

Wang, Q., A. Torzewska, X. Ruan, X. Wang and A. Rozalski et al., 2010. Molecular and genetic analyses of the putative Proteus $O$ antigen gene Locus. Applied Environ. Microbiol., 76: 5471-5478. DOI: 10.1128/AEM.02946-09

Zhang, L., B. Foxman, P. Tallman, E. Cladera and C.L. Bouguenec et al., 1997. Distribution of drb genes coding for Dr binding adhesins among uropathogenic and fecal Escherichia coli isolates and identification of new subtypes. Infect. Immun., 65: 2011-2018. PMID: 9169726

Zingler, G., M. Ott, G. Blum, U. Falkenhagen and G. Naumann et al., 1992. Clonal analysis of Escherichia coli serotype O6 strains from urinary tract infection. Microbial. Pathogenesis, 12: 299310. DOI: 10.1016/0882-4010(92)90048-S 